\title{
Problemas de salud
}

\author{
Health problems
}

Cuando se pregunta a los médicos, y esto es frecuente, cuáles son los principales problemas de salud que afectan a la población, encontramos como respuesta más común que se contesta con una lista de enfermedades. Es también la respuesta habitual de los no médicos, tal vez influidos por estos.

Esta es una respuesta reduccionista, que no va más allá de la enfermedad como fenómeno individual. Es una respuesta influenciada por la tradicional hegemonía del pensamiento médico sobre los asuntos relativos a la salud. Pero no es una respuesta adecuada. Son numerosos y de gran repercusión los determinantes que hoy configuran la salud de las poblaciones.

La salud y la enfermedad obedecen a muy numerosas y diversas determinantes, generalmente las más mencionadas son las biológicas, en estos tiempos sobre todo lo concerniente a la genética. Pero son muy importantes también las políticas, económicas y sociales, que a pesar de estar identificadas desde siempre, se colocan generalmente en un segundo plano.

Reuniéndolos en grandes grupos mencionaré cinco problemas que juzgo de capital importancia para la salud humana: la pobreza, la violencia, la globalización económica neoliberal, la degradación ambiental y los estilos de vida.

Cada grupo o categoría posee cierta complejidad.

La pobreza. Su expresión más grave es la pobreza extrema o indigencia, que lleva al hambre, carencia de vivienda y vestuario, en fin a la enfermedad. Ya en su célebre disertación de 1790, Johan Peter Frank afirmó que la miseria era la madre de todas las enfermedades.

La violencia. Guerra, terrorismo, violencia doméstica (contra niños, mujeres y ancianos), enfrentamientos religiosos, étnicos, crimen organizado, accidentes, migraciones forzadas por la violencia.

La globalización neoliberal. Reducción del papel del estado, desmonte del estado de bienestar, desregulación laboral, privatización de la seguridad social y otros 
servicios públicos, trabajos estresantes y despersonalizados, corrupción.

Narcotráfico. Producción de biocombustibles afectando la producción de alimentos.

La degradación ambiental. Calentamiento climático, mayor frecuencia e intensidad de los desastres naturales, contaminación, desertificación, escasez de agua potable, reducción de la biodiversidad. Saneamiento ambiental deficiente.

El estilo de vida. Sedentarismo, adicciones (en especial tabaco y alcohol), malos hábitos en el consumo de alimentos, consumismo, individualismo. Patrón de fecundidad que adopta la población. Abuso y mal uso de nuevas tecnologías, deterioro de la práctica clínica.

De cada una de estas categorías se ha documentado de modo exhaustivo sus efectos nocivos sobre la salud. Pero generalmente luchamos contra las enfermedades, aisladamente mediante programas específicos. Esto es luchar contra las consecuencias. No dudamos de los beneficios de estos programas. Pero una política que enfrente primero estos problemas enumerados (y otros de igual carácter) podría llevar a resultados de mayor alcance y mayor sostenibilidad.

Los programas contra enfermedades en su mayoría llegan tarde, llegan al enfermo. Se concentran en la terapéutica. No privilegian la promoción y prevención, que son la piedra angular de la lucha contra los problemas enumerados. Esto incluye la lucha política, que denuncia la situación que en el sistema social imperante en el mundo, el capitalismo, dan base de sustentación a estos determinantes de la enfermedad. Estas denuncias son armas indispensables de los que luchan por la salud de los pueblos. Se añade a las armas científico técnicas.

El panorama expuesto tiene un horizonte mundial, pero en cada categoría podemos encontrar algún elemento presente en la situación de salud de Cuba, que no es la de nuestro entorno latinoamericano, ni la de África.

Cuando encontramos dengue, vemos que está presente el deficiente saneamiento ambiental y la escasez de agua. Se asocia el sedentarismo y los malos hábitos alimentarios a la aparición de la obesidad y la diabetes. Como el cáncer de pulmón con las altas tasas de fumadores.

Nuestra situación no es lo crítica que se presenta para otros numerosos países, la mayoría de la población mundial, pero debemos reflexionar frente a estos problemas y enfocar la lucha contra los propios desde una política de salud abarcadora de toda la población con objetivos de promoción y prevención, además de aplicar programas específicos según enfermedades.

Un ejemplo de atención prioritaria que debe observar el sector de la salud, y otros, es la muy baja fecundidad de la población cubana, y su consecuencia más notable sobre la situación de salud, el envejecimiento de la población y la pérdida de su reemplazo. 